The Progressive Fish Culturist, Vol. 58, No. 1, 1996, pp.32-37.

(C) American Fisheries Society

ISSN: $1548-8640$

DOI: $10.1577 / 1548-8640(1996) 058<0032:$ SPACIM $>2.3 . C O ; 2$

http://afs.allenpress.com/archive/1548-8640/58/1/pdf/i1548-8640-58-1-32.pdf

http://afs.allenpress.com/perlserv/?request=get-archive

\title{
Sperm Production and Cryopreservation in Muskellunge after Carp Pituitary Extract and Human Chorionic Gonadotropin Injection
}

\author{
FENG LIN, ANDRZEJ CIERESZKO, KONRAD DABROWSKI
}

\begin{abstract}
We investigated the effects of carp pituitary extract (CPE) and human chorionic gonadotropin (hCG) on the sperm production in muskellunge Esox masquinongy. Total volumes of milt collected from fish (mean weight, $4.8 \pm 1.5 \mathrm{~kg}$ ) injected with CPE, hCG, or the saline control were $5.36 \pm 3.75 \mathrm{~mL}, 3.1 \pm 1.52 \mathrm{~mL}$, and $3.89 \pm 2.16 \mathrm{~mL}$, respectively. Sperm concentration, protein and mineral concentrations of semen, and osmolality of seminal plasma were similar in control and hormonally treated fish. Hormonal injections did not affect the initial percentage of motile sperm compared to untreated fish. However, motility of sperm from the CPE group was lower than for the saline group at $75 \mathrm{~s}$ after activation (statistical significance was $P=0.06$ ). The fertilizing capacities of spermatozoa after cryopreservation from CPE-injected fish were similar to, if not better than, control fish. We report here, for the first time, the successful cryopreservation of muskellunge semen, which produced $30.1 \pm 3.8 \%$ survival to the eyedembryo stage versus $72.9 \pm 8.7 \%$ survival obtained with fresh semen.
\end{abstract}

The sport fishery for muskellunge Esox masquinongy in central North America relies on annual artificial propagation and stocking of fingerlings to maintain the population. However, the small amount of semen that can be stripped from male muskellunge has limited production in some hatcheries. Thus, it would be desirable to increase milt production from fish caught during routine hatchery operation and to induce spermiation 1 year ahead of normal maturation. Hormonal induction of spermiation has been used to increase milt production and achieve out-ofseason spawning in several fish species (see review by Donaldson and Hunter 1983). Spermiation has been induced by injection or implantation of luteinizing hormone releasing hormone analogue (LHRHa) in black porgy Acanthopagrus schlegeli (Yueh et al. 1990) and yellow perch Perca flavescens (Dabrowski et al. 1994). Gonadotropin-releasing hormone $(\mathrm{GnRH})$ and human chorionic gonadotropin (hCG) have been used with striped bass Morone saxatilis (Hodson and Sullivan 1993). Salmon pituitary preparations and a GnRH analogue have been successfully used with Pacific herring Clupea pallasi (formerly C. harengus pallasi; Kreiberg et al. 1987). Carp pituitary extract (CPE) was proved to work well at inducing spermiation in common carp Cyprinus carpio (Saad and Billard 1987). Hormones have also been applied to induce year-round spermiation of carp in some laboratories (Redondo-Muller et al. 1991). However, semen obtained from these hormonally treated fish was highly variable in volume, osmotic pressure of seminal plasma, and sperm motility. Ionic concentrations of seminal plasma are important to maintain sperm motility; however, data on these concentrations after hormonal treatment are not available. Hasler et al. (1940) demonstrated the effectiveness of intraperitoneal injection of $50 \mathrm{mg}$ of acetone-dried carp pituitary gland in stimulating ovulation in captive muskellunge. To our knowledge, no study has been published on hormone injection of muskellunge males.

Using muskellunge maintained in seminatural conditions at a Kentucky hatchery, we studied sperm production of and monitored sperm quantity and quality from fish injected with CPE and hCG. We also analyzed the ionic composition of seminal plasma after hormonal 
treatment. In addition, we developed a method of cryopreservation for muskellunge semen and examined sperm fertility using cryopreserved semen in a comparative study.

\section{Methods}

The experimental fish were muskellunge broodstock (total length range, 762-991 mm) maintained in hatchery ponds for several seasons at the Minor E. Clark Fish Hatchery, Morehead, Kentucky. On April 11, 1994, 18 males were captured from a broodstock pond by electrofishing and were randomly divided into three groups. The length of each fish was measured, and body weight was calculated from a weight-length relationship (D. Brewer, Minor E. Clark Fish Hatchery, personal communication). The hormone dose was determined for each individual. Seven fish were injected intraperitoneally with CPE (Stoller Fisheries, Iowa) at 3.3 $\mathrm{mg} / \mathrm{kg}$ body weight (BW). Five fish were injected with hCG (Sigma, Missouri) at 1,000 IU/kg. Six fish were injected with the vehicle solution $(0.7 \% \mathrm{NaCl})$ to serve as a control. The fish were fin clipped (pelvic fin) and were kept in 0.4-ha ponds in the hatchery. After 2-3 d, the injected fish were recaptured by electrofishing and transferred into indoor troughs during two subsequent days of semen collection (days 3 and 4 postinjection). Fish were anesthetized with a 100-mg/L solution of tricaine methanesulfonate (MS-222) and hand stripped for semen. Semen was collected with a 3-mL disposable syringe in order to estimate the volume and to avoid contamination with urine. The fish were maintained at a water temperature of $12.5^{\circ} \mathrm{C}$ during the experimental period.

Gametes were also collected from Clear Fork Reservoir, Ohio, on April 25, 1994. Mature muskellunge were captured by trap net and hand stripped for gametes without anesthetic. Semen samples were stored on ice before being used for cryopreservation experiments or for fertilization. Eggs were stored in plastic bags and maintained at approximately $12^{\circ} \mathrm{C}$ in a foam box until fertilization.

Semen samples from individual Kentucky fish were kept in vials and stored on ice until use. Sperm concentration was estimated by measuring the optical density (OD) of semen (1:1,000 dilution) with a Beckman DU-70 spectrophotometer at $610 \mathrm{~nm}$ (Ciereszko and Dabrowski 1993) and calculated according to the formula: sperm concentration $=(58.3 \times$ OD + $0.305) \times 10^{9} \mathrm{sperm} / \mathrm{mL}$. Sperm motility was estimated after activation with $25 \mathrm{mM} \mathrm{NaCl}$ in 30 $\mathrm{mM}$ tris- $\mathrm{HCl}(\mathrm{pH} 8.0)$ at room temperature $\left( \pm 18^{\circ} \mathrm{C}\right)$ from the semen collected at day 3 postinjection. The dilution ratio was 1:200. At regular intervals after activation, sperm motility was estimated to the nearest $10 \%$ under a light microscope. Semen samples from day 3 were centrifuged at 12,000 revolutions/min for 10 min with a Beckman Microfuge 12 to separate seminal plasma. Seminal plasma samples were stored on dry ice and later transferred to a BioFreezer $\left(-80^{\circ} \mathrm{C}\right)$. Osmolality of seminal plasma was measured by a microosmometer ( $\mu$ OSMETTER, Precision Systems, Massachusetts). The instrument was calibrated with 100 and 500 milliosmols (mosmol)/kg osmometry standards (Precision Systems) before samples were measured. Potassium, sodium, magnesium, calcium, phosphate, and chloride concentrations in semen collected at day 3 postinjection were measured with an inductively coupled plasma emission spectrometer (ICP, model ARL-3560, Applied Research Laboratory, Valencia, California). Protein concentration was measured by the standard Bradford method (Bradford 1975); bovine albumin (Bio-Rad, Richmond, California) was used as the standard.

Because no eggs were available to evaluate sperm fertility at the time semen was collected from hormone-injected fish, the semen was cryopreserved for later evaluation. Semen collected at day 4 postinjection was kept on ice and transported back to our laboratory in 
Columbus, Ohio. Semen from individual fish was diluted (1:4) with an extender containing 0.6 M sucrose, 10\% dimethyl sulfoxide (DMSO), and 10\% hen's egg yolk (Holtz 1993). Immediately after dilution, $0.1-\mathrm{mL}$ aliquots of sperm suspension were pelleted onto dry ice. After 3-5 min, pellets were transferred into vials and stored in liquid nitrogen (Ciereszko et al. 1993). Two weeks later, two pellets $(0.2 \mathrm{~mL})$ of cryopreserved sperm of each individual were thawed in $5 \mathrm{~mL}$ of a thawing solution $(25 \mathrm{mM} \mathrm{NaCl}$ in $30 \mathrm{mM}$ tris- $\mathrm{mCl}, \mathrm{pH}$ 8.0) at room temperature. The suspension was poured over a batch of 300 eggs immediately after being thawed (6-8 s). After washing, eggs were then divided into two groups and incubated in small baskets set in California-type hatching trays (Flex-a-lite Consolidated, Tacoma, Washington) with flowing water at $12^{\circ} \mathrm{C}$. Eggs were obtained from three muskellunge females collected on April 25 from Clear Fork Reservoir and were pooled for use in this experiment. Some of these eggs were fertilized with fresh semen (Ohio males, $N=6$ ) to serve as a control for egg quality. Semen samples collected from six males from Clear Fork Reservoir were cryopreserved and stored in the manner described above. These semen samples were then thawed in the thawing solution mentioned above (OH1) or in a second thawing solution $(50 \mathrm{mM} \mathrm{NaCl}$ in $30 \mathrm{mM}$ tris$\mathrm{HCl} \mathrm{pH} \mathrm{8.0,} \mathrm{room} \mathrm{temperature;} \mathrm{OH} 2$ ) and were used to fertilize eggs from the same batch for comparison. Survival to eyed-stage embryos (7-9 d old) was determined and used as a criterion for sperm fertility.

TABLE 1. - Mean $( \pm \mathrm{SD})$ characteristics of semen from muskellunge treated with human chorionic gonadotrophin (hCG), carp pituitary extract (CPE), or saline. Milt was collected on days 3 and 4 postinjection. Single asterisk (*) denotes semen volume for that treatment group was significantly larger on day 3 than on day $4(P<0.001)$; double asterisk $(* *)$ denotes sperm concentration was significantly lower than that of saline (control) group on day $4(P<0.05)$.

\begin{tabular}{|c|c|c|c|c|c|c|c|c|}
\hline \multirow[b]{2}{*}{$\begin{array}{l}\text { Treat- } \\
\text { ment } \\
\text { group }\end{array}$} & \multirow[b]{2}{*}{$\begin{array}{l}\text { Fish } \\
\text { weight } \\
(\mathrm{kg})\end{array}$} & \multicolumn{2}{|c|}{ Day 3} & \multicolumn{2}{|c|}{ Day 4} & \multirow[b]{2}{*}{$\begin{array}{c}\text { Total semen } \\
\text { volume } \\
\text { (mL/fish) }\end{array}$} & \multirow[b]{2}{*}{$\begin{array}{l}\text { Semen } \\
\text { volume } \\
\text { per unit } \\
\text { body } \\
\text { weight } \\
(\mathrm{mL} / \mathrm{kg})\end{array}$} & \multirow[b]{2}{*}{$\begin{array}{l}\text { Number of } \\
\text { sperm } \\
\text { per male } \\
\text { (109 sperm/ } \\
\text { male) }\end{array}$} \\
\hline & & $\begin{array}{c}\text { Semen } \\
\text { volume } \\
(\mathrm{mL} / \mathrm{fish})\end{array}$ & $\begin{array}{c}\text { Sperm } \\
\text { concen- } \\
\text { tration } \\
\left(10^{9} \text { sperm/ }\right. \\
\mathrm{mL})\end{array}$ & $\begin{array}{c}\text { Semen } \\
\text { volume } \\
\text { (mL/fish) }\end{array}$ & $\begin{array}{c}\text { Sperm } \\
\text { concen- } \\
\text { tration } \\
\left(10^{9} \text { sperm/ }\right. \\
\text { mL) }\end{array}$ & & & \\
\hline $\mathrm{hCG}$ & $4.76 \pm 1.55$ & $2.62 \pm 1.23^{*}$ & $19.73 \pm 3.95$ & $0.48 \pm 0.42$ & $21.09 \pm 3.15$ & $3.10 \pm 1.52$ & $0.63 \pm 0.22$ & $61.74 \pm 31.59$ \\
\hline CPE & $4.87 \pm 1.56$ & $4.47 \pm 3.61^{*}$ & $19.35 \pm 1.81$ & $1.03 \pm 0.76$ & $18.26 \pm 3.1^{* * *}$ & $5.36 \pm 3.75$ & $1.13 \pm 0.66$ & $83.52 \pm 35.87$ \\
\hline Saline & $4.81 \pm 1.59$ & $3.19 \pm 1.83^{*}$ & $20.55 \pm 2.10$ & $0.70 \pm 0.46$ & $21.16 \pm 1.74$ & $3.89 \pm 2.16$ & $0.84 \pm 0.47$ & $60.66 \pm 27.82$ \\
\hline
\end{tabular}

All variables were expressed as mean \pm SD. The statistical significance of sperm motility was assessed by two-way analysis of variance (ANOVA) with the Proc GLM procedure in SAS, (version 6.07; SAS Institute, Cary, North Carolina). The statistical package StatView (Abacus Concepts, Berkeley, California) was used for Student's $t$-tests for sperm production, concentration, and fertility comparison.

\section{Results and Discussion}

Fish treated with CPE had a better yield in terms of semen volume, volume per kilogram of body weight, and number spermatozoa per male than fish treated with hCG or saline, although no statistically significant differences were found when results from days 3 and 4 were combined (Table 1). Total volume of semen per fish ranged from 0.85 to $12.9 \mathrm{~mL}$. Volume of sperm production at day 3 postinjection was significantly higher than that of day 4 in all groups $(P<$ 0.001). Sperm concentration of the CPE group was significantly lower $(P<0.05)$ than that of the 
saline group at day 4, whereas no significant difference was found at day 3. However, there were no significant differences among the three groups for the rest of the variables $(P>0.05)$. The small number of males available to us limited the sample size and prevented the use of fish of uniform size. These differences in fish size might have influenced the hormonal treatment and may have been responsible for the great variation of semen volume, leading to no statistically significant differences. Our results differed from those obtained from another esocid. Billard and Marcel (1980) successfully increased milt production in northern pike Esox lucius by 3-11 times by means of a single injection of partially purified salmon gonadotropin, by 3-7 times with crude carp pituitary extract, and by 3-6 times with fresh pike pituitary extract, whereas an LHRH analogue failed to stimulate milt production.

All samples showed a high percentage of motile sperm (90-100\%) immediately after activation (Figure 1), and the percentage of motile sperm was maintained at over $50 \%$ for $60 \mathrm{~s}$ at room temperature. This motility compares favorably to the northern pike sperm motility of less than a minute of progressive sperm movement reported by Koldras and Moczarski (1983). Hormonal injection did not change the initial percentage of motile sperm. However, motility of sperm from fish treated with CPE was lower than that of sperm from the saline-treated fish at 75 $\mathrm{s}$ after activation (statistically significant at $P=0.06$ ). Spermatozoa from fish treated with hCG did not show any difference of motility compared with sperm from control fish. In contrast, initial percentage of motile sperm ranged from 1 to $100 \%$ in common carp semen from hormonally treated fish (Redondo-Muller et al. 1991).

Major ionic components, $\mathrm{Na}^{+}, \mathrm{K}^{+}$, and $\mathrm{Cl}^{-}$, were slightly higher for the CPE group than for the other two groups, but the differences were not significant (Table 2). We did not find significant changes in the osmolality of seminal plasma or in protein concentrations after hormonal treatments. The seminal plasma for the ionic concentration analysis was prepared from semen collected at day 3 when no differences in semen volume and sperm density were found among three groups. In other fish species, the effect of hormonal treatment to induce spermiation was pronounced. For common carp, osmolality of seminal plasma decreased from 300 mosmols/kg in naturally spawning fish to 258 mosmols/kg after hormonal injection (RedondoMuller et al. 1991). Osmolality of muskellunge seminal plasma was not higher than that of yellow perch (295 mosmols/kg; F.L, and K.D., unpublished data). 


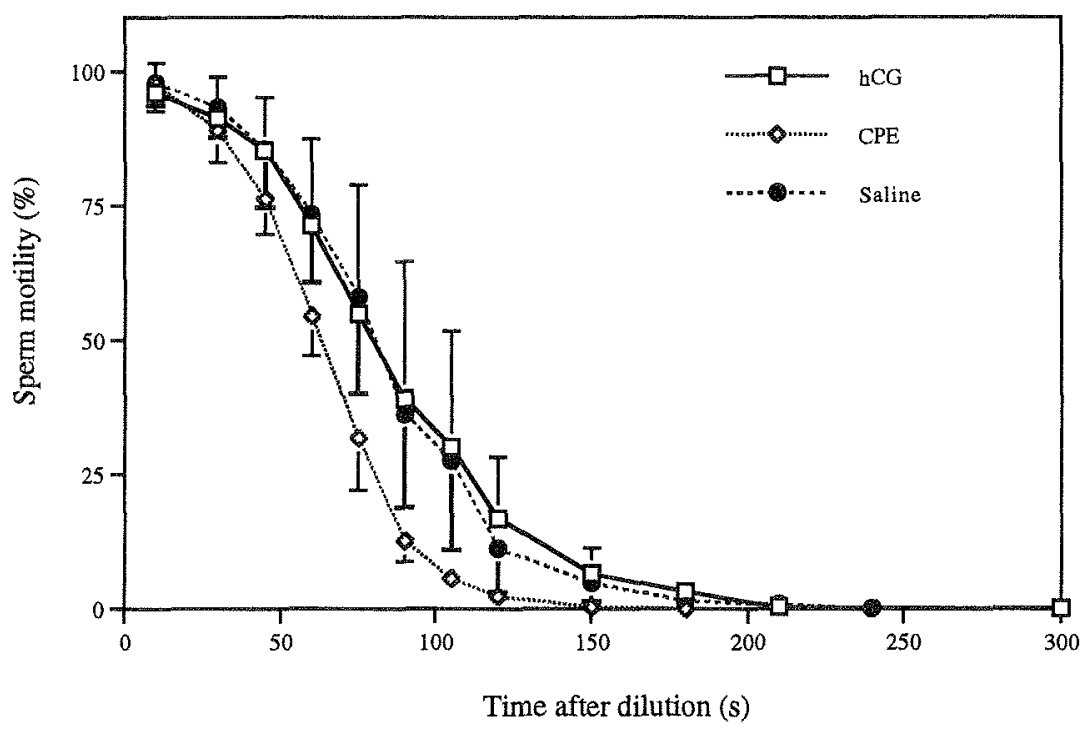

FIGURE 1. - Percentage of motile muskellunge sperm ( \pm SD) in relation to time after dilution. Semen was diluted (1:200) with $25 \mathrm{mM} \mathrm{NaCl}$ in $30 \mathrm{mM}$ tris- $\mathrm{HCl}$ at $\mathrm{pH}$ 8.0. At regular intervals after activation, the percentage of motile sperm was estimated to nearest $10 \%$ under a light microscope ( $N=5-7$ males/treatment group).

Eggs fertilized with fresh semen had a $72.9 \pm 8.7 \%$ survival to the eyed stage, which indicated that the egg quality was good. Fertility of sperm from CPE-treated fish was higher than that of the saline-treated group, although the difference was only marginally significant $(P=$ 0.069; Figure 2). Semen from fish injected with CPE maintained its quality after cryopreservation. Saad and Billard (1987) reported similar fertilizing capacities of the spermatozoa in naturally spawning fish and hormonally treated common carp. Cryopreserved sperm from Clear Fork Reservoir had a significantly higher $(P<0.05)$ fertilizing capacities than that from the hCG and saline groups but not from the CPE group from Kentucky. The difference in storage time before cryopreservation for Kentucky and Ohio semen samples might partially explain the different fertilizing capacities of spermatozoa. Our unpublished results indicated that there was a significant effect of storage time prior to freezing on the success of cryopreserved muskellunge semen. Survival to the eyed stage of eggs that were fertilized with cryopreserved semen thawed in $50 \mathrm{mM} \mathrm{NaCl}(\mathrm{OH} 2$; Figure 2) was $30.1 \pm 3.8 \%$, which was significantly higher than for all other groups $(P<0.01)$. This indicated that thawing solution was an important variable in cryopreservation of muskellunge semen. Fertilization rates obtained in this study compare favorably with that reported by Moore (1991). However, the relatively low fertilization rate with fresh semen reported by Moore (1991) and uncertainties about the semen: egg ratio make direct comparisons of limited value. 
TABLE 2. - Mean ( \pm SD) concentrations of chemicals in muskellunge seminal plasma after injection with human chorionic gonadotropin (hCG), carp pituitary extract (CPE), or saline.

\begin{tabular}{lccr} 
& \multicolumn{3}{c}{ Treatment group } \\
\cline { 2 - 4 } Component & hCG & CPE & \multicolumn{1}{c}{ Saline } \\
\hline Potassium $(\mathrm{mM})$ & $24.45 \pm 2.87$ & $27.18 \pm 2.57$ & $23.69 \pm 1.69$ \\
Sodium $(\mathrm{mM})$ & $135.39 \pm 10.94$ & $137.73 \pm 2.53$ & $131.96 \pm 2.96$ \\
Calcium $(\mathrm{mM})$ & $2.02 \pm 0.20$ & $1.96 \pm 0.07$ & $2.11 \pm 0.19$ \\
Magnesium $(\mathrm{mM})$ & $1.14 \pm 0.21$ & $0.99 \pm 0.10$ & $1.45 \pm 0.61$ \\
Phosphate $(\mathrm{mM})$ & $4.28 \pm 1.16$ & $1.14 \pm 0.47$ & $5.57 \pm 5.57$ \\
Chloride $(\mathrm{mM})$ & $134.18 \pm 6.83$ & $135.66 \pm 5.62$ & $132.32 \pm 7.02$ \\
Protein $(\mathrm{mg} / \mathrm{mL})$ & $0.377 \pm 0.031$ & $0.346 \pm 0.087$ & $0.352 \pm 0.088$ \\
Osmolality & & & \\
(milliosmole/kg) & $286.4 \pm 22.2$ & $292.6 \pm 23.0$ & $284.3 \pm 10.0$
\end{tabular}

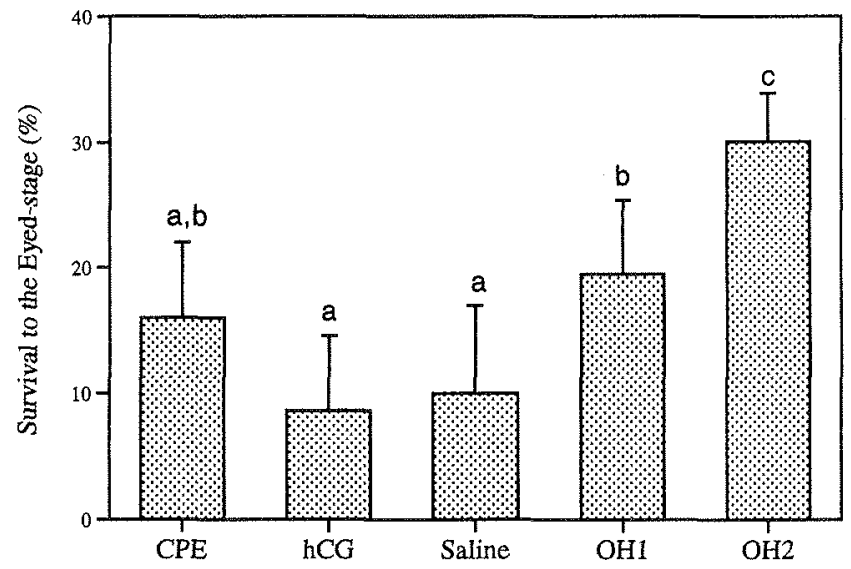

FIGURE 2 .- Mean ( + SD) percent survival of eggs to eyed stage following fertilization with cryopreserved sperm from Kentucky-reared muskellunge that were treated with carp pituitary extract (CPE; $N=7$ ), human chorionic gonadotropin (hCG; $N=5$ ), or saline (control; $N=6$ ) or with cryopreserved sperm from untreated muskellunge from Clear Fork Reservoir in Ohio (OH1 and OH2; $N=6$ for both). The thawing media for the $\mathrm{OH} 2$ semen had a higher $\mathrm{NaCl}$ concentration than that used for the other semen samples. Treatments with the same letters over the bars were not significantly different $(P>0.05)$. Eggs fertilized with fresh semen from Ohio males had $72.9 \pm 8.7 \%$ survival to the eyed stage.

In conclusion, our results suggested that semen collected from CPE-treated muskellunge showed sperm fertility after cryopreservation that was similar to, if not better than, that obtained from control fish. Muskellunge treated with CPE showed improved sperm production, although the difference was not significant. Statistical significance might have been influenced by our small sample size and the large size variation of the fish. We determined the ionic and chemical composition of muskellunge seminal plasma, which will allow us to compose an extender matching natural sperm environment for this species for better aquisition and initiation of sperm motility. We reported here, for the first time, the success of cryopreservation of muskellunge semen, with $30.1 \pm 3.8 \%$ survival of fertilized eggs to the eyed stage. We recommend CPE injection, as practiced by Minor E. Clark Fish Hatchery personnel, as a way to improve sperm 
production in muskellunge and, potentially, to make sperm more suitable for cryopreservation.

\section{Acknowledgments}

We thank Roy A. Stein and John D. Harder of Ohio State University for their critical reading of this manuscript. We are in debt to Dan Brewer and his team at the Minor E. Clark Fish Hatchery, Kentucky, for their provision of experimental materials and facilities. We also thank Frederick S. Roland of Academic Computing Services of Ohio State University for statistical consultation, and we appreciate the helpful cooperation of Richard Day, Frank Kapler, and Bruce Bartens of the Ohio Department of Natural Resources in sampling gametes. This work was funded by Federal Aid in Sport Fish Restoration project F-69-P (Fish Management in Ohio), which is administered jointly by the U.S. Fish and Wildlife Service and the Ohio Division of Wildlife. Salaries were partly provided by state and federal funds appropriated to the Ohio Agriculture and Development Center. This is manuscript 173/95.

\section{References}

Billard, R., and J. Marcel. 1980. Stimulation of spermiation and induction of ovulation in pike (Esox Indus). Aquaculture 21:181-195.

Bradford, M. M. 1975. A rapid and sensitive method for the quantitation of microgram qualities of protein utilizing the principle of protein-dye binding. Analytical Biochemistry 72:248-254.

Ciereszko, A., and K. Dabrowski. 1993. Estimation of sperm concentration of rainbow trout, whitefish, and yellow perch using a spectrophotometric technique. Aquaculture 109:367-373.

Ciereszko, A., L. Ramseyer, and K. Dabrowski. 1993. Cryopreservation of yellow perch semen. Progressive FishCulturist 55:261-264.

Dabrowski, K., A. Ciereszko, L. Ramseyer, D. Culver, and P. Kestemont. 1994. Effects of hormonal treatment on induced spermiation and ovulation in the yellow perch (Perca flavescens). Aquaculture 120: 171-180.

Donaldson, E., and G. A. Hunter. 1983. Induced final maturation, ovulation, and spermiation in cultured fish. Page 351-403 in W. S. Hoar, D. J. Randall, and E. M. Donaldson, editors. Fish physiology, volume 9, part B. Academic Press, New York.

Hasler, A. D., R. K. Meyer, and H. M. Field. 1940. The use of hormones for the conservation of muskel lunge, Esox masquinongy immaculatus Garrard. Copeia 1940:43-46.

Hodson, H. G., and C. V. Sullivan. 1993. Induced maturation and spawning of domestic and wild striped bass, Morone saxatilis (Walbaum), broodstock with implanted GnRH analogue and injected hCG. Aqua-culture and Fisheries Management 24:389-398.

Holtz, W. 1993. Cryopreservation of rainbow trout (Oncorhynchus mykiss) sperm: practical recommendations. Aquaculture 110:97-100.

Koldras, M., and M. Moczarski. 1983. Properties of pike Esox lucius L. milt and its cryopreservation. Polskie Archiwum Hydrobiologii 30:69-78.

Kreiberg, H, G. A. Hunter, E. M. Donaldson, W. C. Clarke, and I. Baker. 1987. Induced ovulation and spermiation in the Pacific herring (Clupea harengus pallasi) using salmon pituitary preparations and synthetic gonadotropin-releasing hormone analogue. Aquaculture 61:155-161.

Moore, A. A. 1991. Refrigerated storage and cryopreservation of walleye and muskellunge semen. Iowa Department of Natural Resources, Technical Bulletin 4, Des Moines.

Redondo-Muller, C, M. P. Cosson, J. Cosson, and R. Billard. 1991. In vitro maturation of the potential for movement of carp spermatozoa. Molecular Reproduction and Development 29:259-270.

Saad, A., and R. Billard. 1987. Spermatozoa production and volume of semen collected after hormonal stimulation in the carp, Cyprinus carpio. Aquaculture 65:67-77.

Yueh, W.-S., S.-F. Lin, and C.-F. Chang. 1990. Effect of LHRH-A and HCG on spermiation volume, concentration of milt and sex steroids in black porgy, Acanthopagrus schlegeli. Journal of the Fisheries Society of Taiwan 17(1):65-72. (In Chinese; English abstract.) 